130

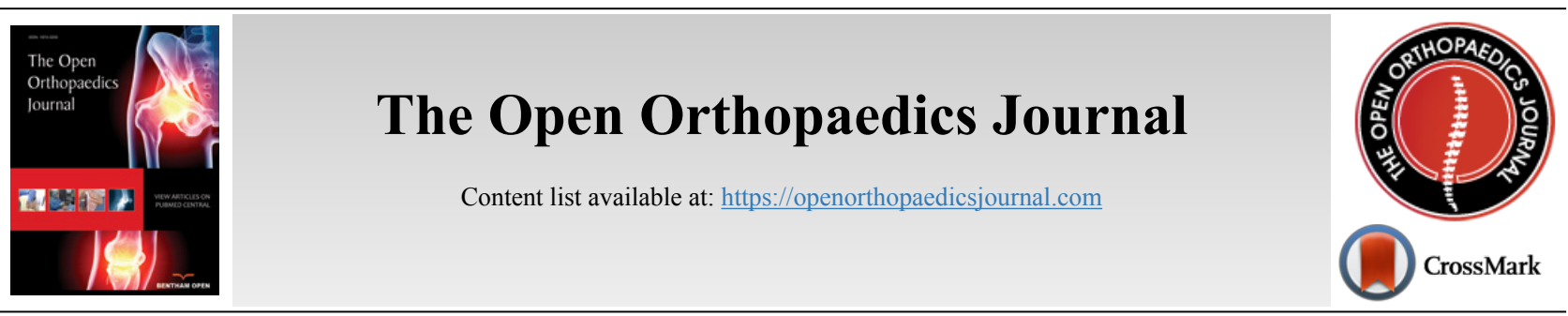

RESEARCH ARTICLE

\title{
Injury Patterns of Equine-Related Trauma
}

\author{
Frank Liaw ${ }^{1, *}$, Siddharth Govilkar ${ }^{1}$, Timothy Woo $^{2}$, Ingrid Britton ${ }^{2}$, Bishoy Youssef $^{1}$ and Justin Lim ${ }^{1}$ \\ ${ }^{\prime}$ Department of Trauma \& Orthopaedics, Royal Stoke University Hospital, Stoke-on-Trent ST4 6QG, United Kingdom \\ ${ }^{2}$ Department of Radiology, Royal Stoke University Hospital, Stoke-on-Trent ST4 6QG, United Kingdom
}

\begin{abstract}
:
Introduction:

Equestrian sports are popular in the United Kingdom (UK), with approximately 2.7 million people of all ages participating in equine-related sports in 2015. These sports are not without risk; the position of the mounted rider puts them at risk of injuries sustained by fall from a height, compounded by movement at speed. The aim of this study was to characterise demographics and injury patterns of equine-related trauma presentations at a major trauma centre in the UK.

Methods:

From a trauma admissions database and electronic search of radiology requests including keywords "equine", "equestrian", "horse", and "pony" with cross-referencing from ICD-10 coding, 144 patients were identified to have presented to an adult major trauma centre with equine-related injuries from falls while mounted over a 3-year period.

Results:

Females accounted for $86 \%$ of patients $(n=123)$. The most common presenting age group was age $20-29$, but most injuries occurred with patients of ages 50-59. Spinal injuries accounted for $41 \%(n=69)$ of all injuries and occurred in a similar proportion in all age groups. Upper limb injuries accounted for $100 \%$ of injuries in those aged $0-9.39 \%(n=56)$ of patients required operative management for their injuries.

\section{Conclusion:}

We have been able to identify which body zones of injury are more at-risk in equine-related sports following falls from mounted riders, and recognize how certain injury patterns may be more prevalent in particular age groups. Spinal injuries have been demonstrated to be a new leading zone of injury, possibly due to stricter legislation from government and industry leading to the relative reduction of head injuries. Reducing the number and severity of these injuries will not only improve patient outcomes but reduce the burden on the healthcare system.
\end{abstract}

Keywords: Equestrian, Equine, Horse riding, Sports injury, Spinal injuries, Trauma.

\begin{tabular}{ll|l|l} 
Article History & Received: November 14, 2018 & Revised: March 03, 2019 & Accepted: March 06, 2019
\end{tabular}

\section{INTRODUCTION}

Equestrian sports are popular in the United Kingdom (UK), with approximately 2.7 million people of all ages participating both professionally and leisurely in equine-related sports in 2015 [1]. These sports inherently involve risk of serious injury, with a study demonstrating injury rates of 1 per 350-1000 hours while mounted [2]. Horseback riding has been determined to cause some of the highest total body injury and mortality rates compared to all other modern sporting activities;

* Address correspondence to this author at Department of Trauma \& Orthopaedics, Royal Stoke University Hospital, Stoke-on-Trent, ST4 6QG, United Kingdom; Tel: +44-178-271-5444; Email: frankliaw@doctors.org.uk this has been established to be more hazardous than either motorcycle riding or rugby $[3,4]$. The high position of the mounted rider puts them at risk of injuries sustained by fall from a height, compounded by the unpredictability of the animal, and movement of both horse and rider at speed. Additional trampling or crush injuries may also be sustained if the horse lands on the rider. Certain equestrian disciplines place riders at even greater risk of falls and ejection, particularly those involving jumping of obstacles.

Despite the popularity of equestrian sports in the UK, high incidence of equine-related injuries, and a significant degree of severity in comparison to other sports, there is a surprising paucity of evidence regarding equine-related trauma, particu- 


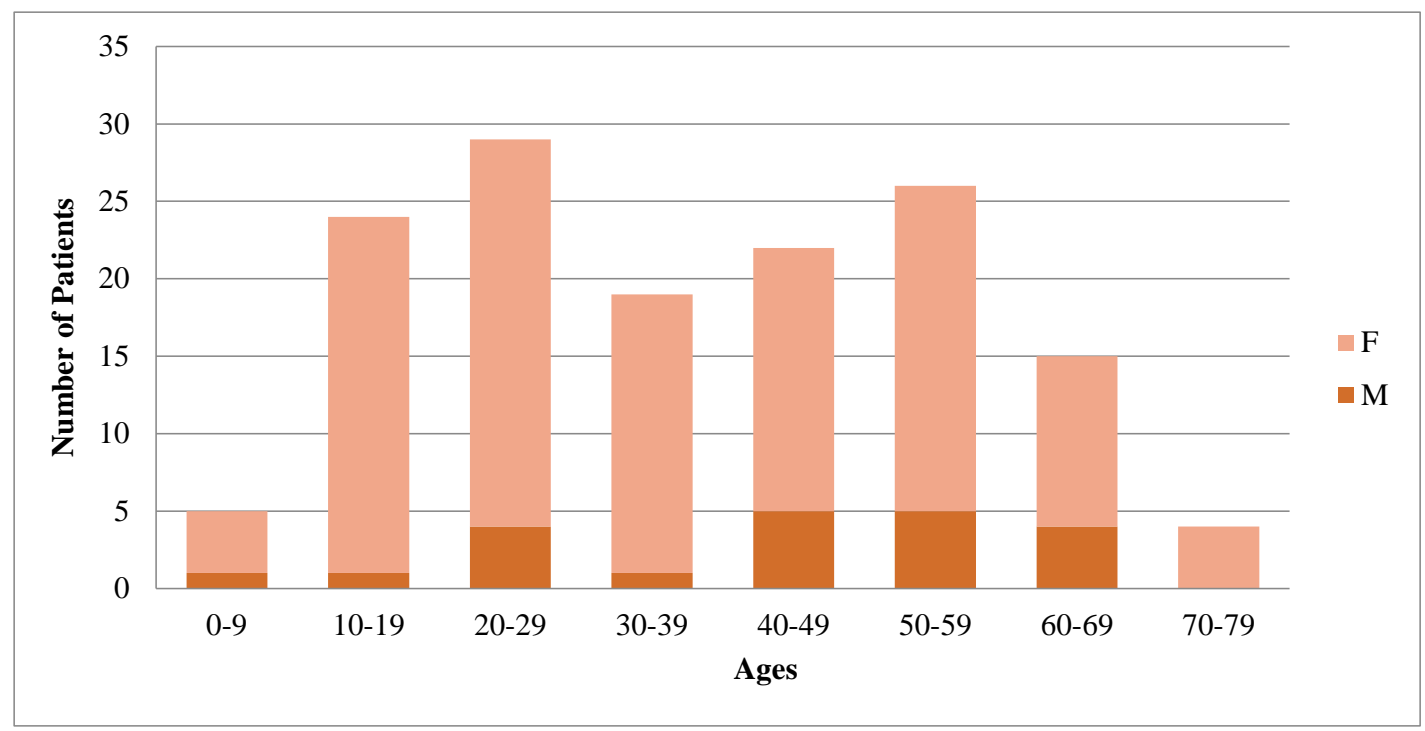

Fig. (1). Patients by age group and gender.

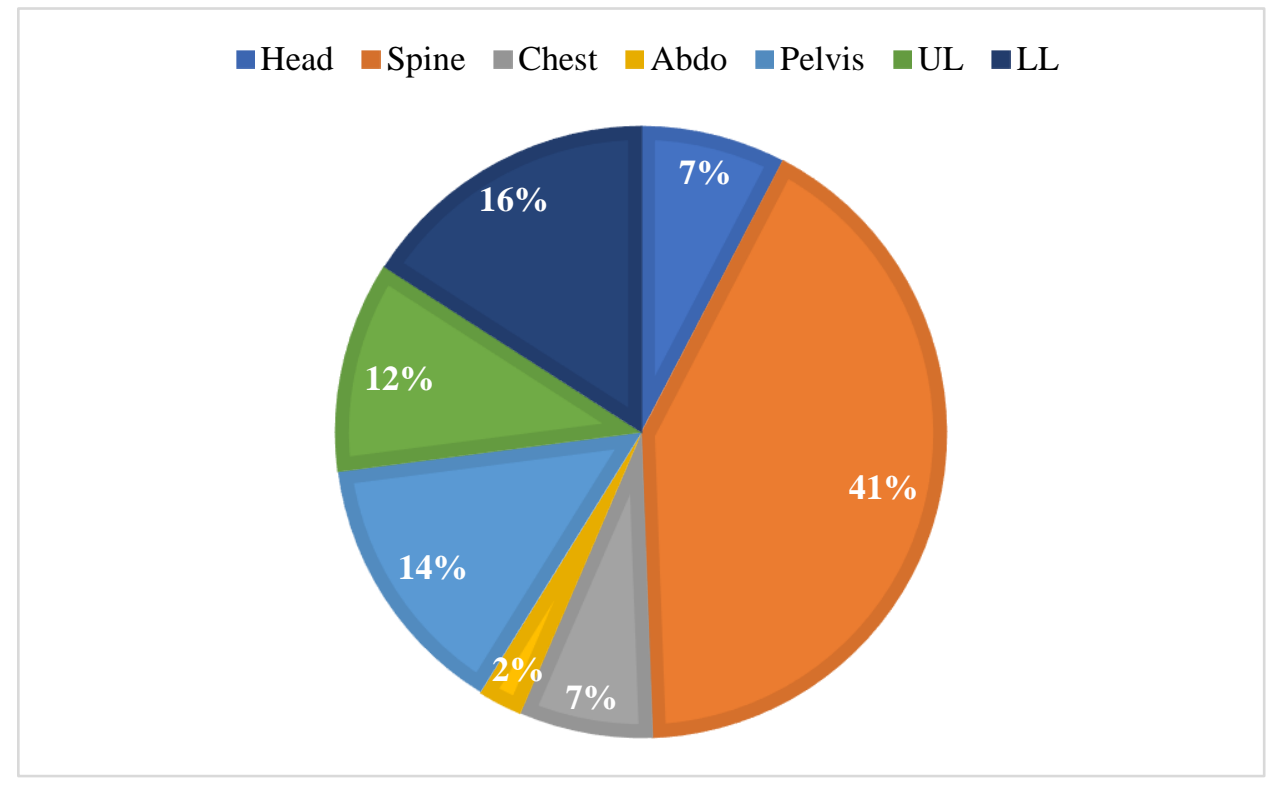

Fig. (2). Body zones of injury.

larly of the demographics, nature of injury and characterisation of injury patterns. The aim of this study was to characterise injury patterns and identify trends of equine-related trauma following falls by mounted riders presenting at a major trauma centre in the UK. Through increasing our understanding of equine-related trauma, we hope to inspire and provide a new direction for future research in the prevention and management of these injuries.

\section{METHODS}

This study included all patients who presented to a large adult major trauma centre in the UK with equine-related injuries from falls while mounted over a 3-year period (01/05/2015-01/05/2018). Patients were identified from electronic searches of the trauma admission database, and electronic records of radiology imaging requests using the following keywords "equine", "equestrian", "horse", and "pony". Patients were cross-referenced with those admitted with ICD-10 diagnosis codes V80.010 (animal-rider injured by fall from or being thrown from a horse in noncollision accident) and V80.018 (animal-rider injured by fall from or being thrown from another animal in noncollision accident). Data was retrospectively collected from electronic records and analysed (including patient demographics, mechanisms of injury, zones of injury, and management). 


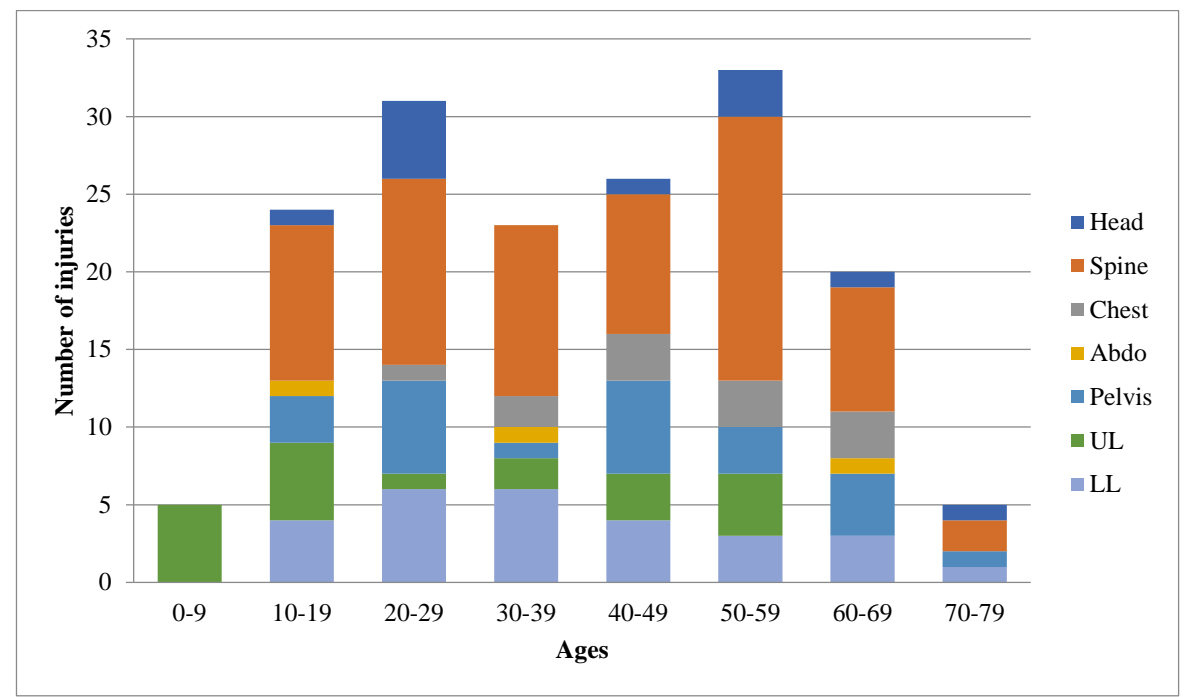

Fig. (3). Number of injuries by age group and body zones.

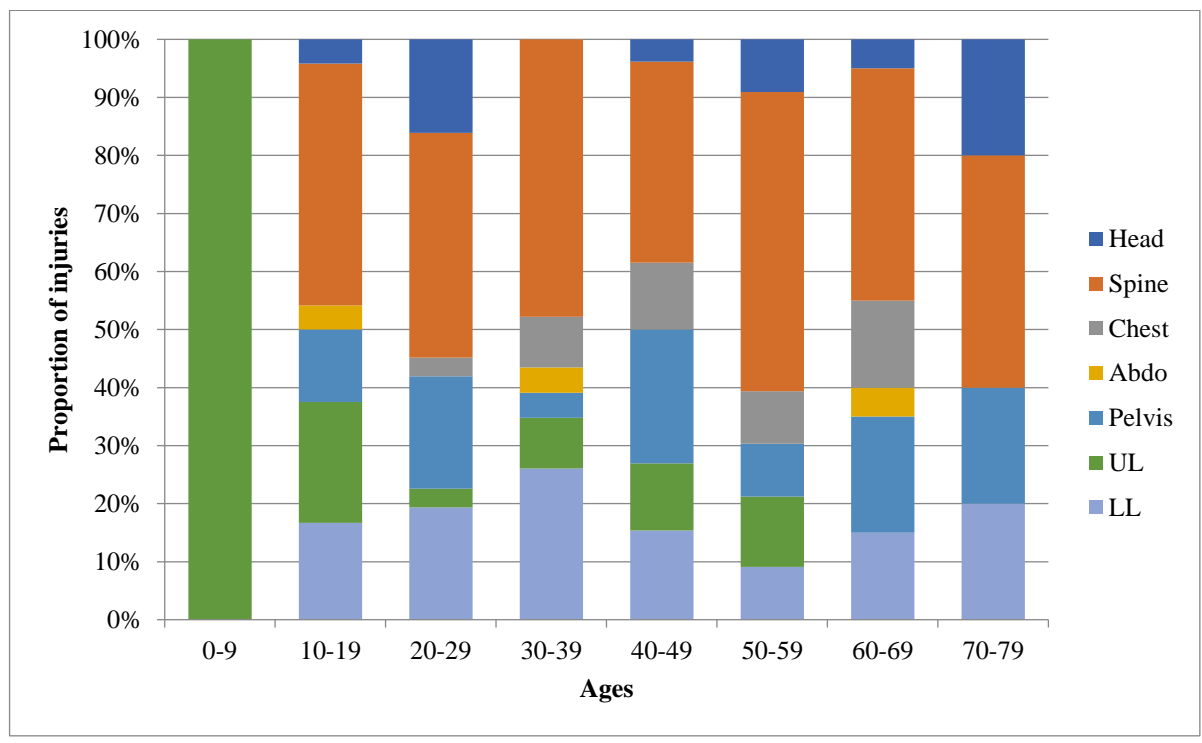

Fig. (4). Proportion of injuries by age group and body zones.

\section{RESULTS}

A total of 144 patients were identified and included in this study.

\subsection{Demographics}

Females accounted for $86 \%$ of patients $(n=123)$. A bimodal distribution of patients can be demonstrated, with the most commonly presenting patients of ages 20-29 ( $\mathrm{n}=29$; $20 \%)$ followed by those of ages $50-59(n=26 ; 18 \%)$ (Fig. 1).

\subsection{Injuries}

The most common body zones injuries were, in descending order of prevalence, spinal, lower limb, pelvic, upper limb, head, chest, and abdominal. $41 \%$ of injuries were spinal injuries (Fig. 2). 39\% $(\mathrm{n}=56)$ of patients required operative management for their injuries. The 50-59 age group sustained the most injuries (Fig. 3). All the patients within the 0-9 age group had sustained only upper limb injuries. Apart from this age group, spinal injuries appeared consistent across all remaining age groups (Fig. 4).

\section{DISCUSSION}

Equestrian sports are inherently dangerous; approximately 1 in 5 riders will sustain a serious injury over the course of their riding career. Horses can be unpredictable animals which weigh 1500 kilograms on average and can sprint at up to 50 miles per hour [5]. Riders are perched above them, at risk of falls and ejection, with their heads positioned at approximately 3 metres above the ground. Both horse and rider are often pushed to their physical limits, particularly when involved in events, which place them at further risk of injury.

Equestrian sports have always had a strong gender bias, with approximately $74 \%$ of riders being female [1]. Our study 
found that $86 \%$ of equine-related trauma occurred in female riders. Although this is not a dissimilar proportion of injuries relative to the number of female riders, Weber et al. have in fact determined female riders to be at a higher risk of sustaining falls from height than their male counterparts [6]. In addition, Majeedkutty et al. demonstrated a significant correlation between the female gender and the prevalence of horseback riding injuries [7].

The most commonly presenting age groups were those of ages $20-29(\mathrm{n}=29 ; 20 \%)$ followed by those of ages $50-59(\mathrm{n}=$ $26 ; 18 \%$ ). This bimodal distribution may be due to a variety of reasons. The peak in injuries at ages 20-29 most likely reflects the higher number of horseback riders within this age range; according to the UK National Equestrian Survey in 2015, there has been a particularly significant increase in the number of all riders ages 16-24 [1]. In addition, there were two professional horse jockeys within this age group. This would be consistent with the general trend of this occupation, which starts licensing at age 16 [8].

The second peak of injuries at age 50-59 may again be attributed to high participant numbers in this age group, compounded by comorbidities such as osteoporosis which increase the risk of injury. It is interesting to note that although the 50-59 age group is the second most prevalent age group in this patient cohort $(\mathrm{n}=26 ; 18 \%)$, they sustained the largest number of injuries $(\mathrm{n}=33 ; 20 \%)$. Comorbidities such as osteoporosis may not only increase the risk of presentation with an injury associated with a less severe mechanism, but also the risk of more injuries with each incident.

A quarter of all paediatric sports fatalities are due to equine-related injuries [9]. However, none of the paediatric admissions in our study resulted in mortality. All injuries sustained by patients up to 9 years old involved the upper limb, while the majority of those aged 10 to 19 had sustained spinal $(\mathrm{n}=10 / 24 ; 42 \%)$ and upper limb $(\mathrm{n}=5 / 24 ; 21 \%)$ injuries. Wolyncewicz et al. had noted upper limb fractures and spinal injuries to be more prevalent in mounted versus unmounted paediatric patients aged 16 and below. While Wolyncewicz et $a l$. had found head injuries to be the most common horserelated injury in children, unmounted riders were also noted to be more than 8 times as likely to sustain a severe head injury [9]. In comparison, our inclusion criteria had included only mounted riders. This may be responsible for the relative lack of head injuries in our patient group. The difference between helmet laws in young equestrian riders may also accountable. Their study had been performed in Australia, where there is currently no government legislation that mandate helmet use in young equestrian riders. A further retrospective cohort study performed at a paediatric trauma hospital in Australia also demonstrated the most common horse-related injuries to be traumatic brain injuries (24.6\%) followed by upper limb fractures $(20.9 \%)$ [10].

In adults, there appear to be differences from reported incidences of injuries to different body regions. The most frequently injured body regions were demonstrated to be the spine $(41 \%)$, lower limb (16\%) and pelvis (14\%). This differs from what has been previously reported in the literature; Schröter et al. found the head (17.5\%), upper limbs (17.4\%), and thoracic and lumbar spine $(12.9 \%)$ to be the most frequently injured body regions in falls from horses in Germany [11]. In comparison, Ball et al. demonstrated the chest $(54 \%)$, head $(48 \%)$, and abdomen $(22 \%)$ to be the most frequently involved body regions in all horse-related injuries [3].

Hamilton et al. noted, in 1993, that the prevalence of head injuries was six times that of spinal injuries [12]. In comparison, our results demonstrate the opposite; spinal injuries were nearly six times more prevalent than head injuries. As helmets have been shown to lead to a $50 \%$ risk reduction of injury, this may be attributed to the increased use of protective riding hats in the UK in recent years led by increased public awareness, UK legislation and rules set by UK equestrian sport governing bodies [13]. UK Highway Code rule 49 specifies that all riders under age 14 must wear a helmet compliant with regulations [14]. Although there is no legal requirement for adults to wear head protection, helmet use is compulsory at UK horse riding club competitions and events which have strict helmet standards.

Our results demonstrate that spinal injuries account for $41 \%(n=69)$ of all injuries and occur in a similar proportion in all age groups. It has been postulated that the pattern of spinal injury is related to the position of the rider, with the rider either jockey style in a head-first position leading to cervical injuries, or a classical style in a seated upright position where thoracolumbar injuries are more likely to occur [15]. Body protectors, although less often worn than helmets, are required to meet a certain standard and are also compulsory at certain UK horse riding club events. However, the European safety standard BETA EN13158: 2009 level 3 protection, the highest level of body protector, was only required to prevent "minor bruising that would have produced stiffness and pain, reduce soft tissue injuries and bruising, and prevent a limited number of rib fractures" [16]. Body protectors have been shown to have a variable benefit at reducing torso injury, with no evidence in the current literature of reducing the risk or severity of spinal injuries [17 - 19]. Further research is necessary regarding the role of body protectors or alternative safety equipment, such as air jackets, in reducing the risk of spinal injuries.

$39 \%(n=56)$ of these patients required operative management for their injuries, representing significant morbidity associated with these injuries and resulting burden on the healthcare system. The majority of these operations were orthopaedic, such as open reduction and internal fixation of various fractures, spinal cord decompression, spinal stabilisation, and pelvic fixation. Other procedures included depressed skull fracture elevation, and damage control surgery, such as emergency laparotomy and splenectomy.

We noted poor documentation in admission notes, particularly with recognized risk factors associated with severe trauma. This includes details of the background and mechanism of injury, rider experience level, and whether perso-nal protective equipment had been worn during the injury [3]. Disciplines recognised to be associated with increased risk of injury include point-to-point, hunting, and the cross-country phase of eventing, due to their competitive 
nature and need to navigate obstacles at speed [20]. Types of personal protective equipment include helmets, gloves, boots, and body protectors, which have been demonstrated to have variable effectiveness at reducing the incidence and severity of head, truncal, and lower limb injuries [17, 21, 22]. Standardised documentation may improve clinical suspicion of injuries, thus enabling early recognition and management of injuries.

There are several limitations of our study. Hospital injury coding systems are unreliable for the use of coding equinerelated injuries with ICD-10. As such, we have used this to further cross-reference a patient list obtained by reviewing a trauma admissions database, supplemented by radiology requests with specified search terms. Minor injuries which did not necessitate presentation to hospital, radiological investigation or specialist input will be unreported and not captured in our data set. The numbers of patients in the $0-9$ and 10-19 age groups may also be underrepresented as the hospital is not a designated paediatric major trauma centre. In addition, this study only investigated equine-related trauma due to falls, as it was not within the scope of this study to consider alternative mechanisms of injury which had occurred while unmounted. Although falls account for the majority of equine-related trauma, up to $94.9 \%$ in a particular study, unmounted riders may also be at risk of additional injuries [23]. We aim to further explore this area in future research, as more prospective studies are required. As more knowledge accumulates, we can further clarify risk factors for severity of injury which can be used to develop standard-ized documentation to improve early recognition of injuries.

Further steps to improve rider safety will include implementing guidelines and regulations for injury prevention. Additional research, particularly regarding the role of body protectors or alternative safety equipment in reducing the risk of spinal injuries, will first be required in order to guide UK legislation and rules to be set by UK equestrian sport governing bodies.

As a pre-modern sport, injuries sustained with equestrianism have been demonstrated throughout history [24]. It is, however, no longer adequate to simply accept that injuries will occur. 144 patients had presented over three years, which translates to approximately one patient a week; patients with equine-related trauma represent a perceptible proportion of admissions to a major trauma centre, a significant proportion of whom require operative management. Further research is required regarding the role of body protection systems and additional variables in the prevention of these injuries.

\section{CONCLUSION}

We have been able to identify which body zones of injury are more at risk in equine-related sports and recognize how certain injury patterns may be more prevalent in certain age groups. Spinal injuries have been demonstrated to be a new leading zone of injury, possibly due to stricter legislation from government and industry leading to the relative reduction of head injuries. A significant proportion of patients require operative management following admission. Reducing the number and severity of these injuries will not only improve patient outcomes but reduce the burden on the healthcare system. Further research is required regarding additional variables and the role of body protection systems in equestrian sports.

\section{ETHICS APPROVAL AND CONSENT TO PARTICIPATE}

Not applicable.

\section{HUMAN AND ANIMAL RIGHTS}

No animals/humans were used for studies that are the basis of this research.

\section{CONSENT FOR PUBLICATION}

Not applicable.

\section{CONFLICT OF INTEREST}

The authors declare no conflict of interest, financial or otherwise.

\section{ACKNOWLEDGEMENTS}

FL: involved in the conception of the work, data collection, data analysis and interpretation, preparation of manuscript, literature review, and revision of the manuscript. SG: involved in data analysis and interpretation, and preparation of the manuscript. TW: involved in data collection, data analysis and interpretation. IB: involved in the conception of the work, and revision of the manuscript. BY: involved in data analysis and interpretation, and preparation of the manuscript.

JL: involved in the conception of the work, preparation of the manuscript, revision of the manuscript and supervision.

\section{REFERENCES}

[1] British Equestrian Trade Association. National Equestrian Survey. http://www.beta-uk.org/pages/industry-information/market-informatio n.php. Accessed 12 July 2018.

[2] Carmichael SP II, Davenport DL, Kearney PA, Bernard AC. On and off the horse: Mechanisms and patterns of injury in mounted and unmounted equestrians. Injury 2014; 45(9): 1479-83. [http://dx.doi.org/10.1016/j.injury.2014.03.016] [PMID: 24767580]

[3] Ball CG, Ball JE, Kirkpatrick AW, Mulloy RH. Equestrian injuries: Incidence, injury patterns, and risk factors for 10 years of major traumatic injuries. Am J Surg 2007; 193(5): 636-40.

[http://dx.doi.org/10.1016/j.amjsurg.2007.01.016] [PMID: 17434372]

[4] Zuckerman SL, Morgan CD, Burks S, et al. Functional and structural traumatic brain injury in equestrian sports: A review of the literature. World Neurosurg 2015; 83(6): 1098-113.

[http://dx.doi.org/10.1016/j.wneu.2014.12.030] [PMID: 25535066]

[5] Havlik HS. Equestrian sport-related injuries: A review of current literature. Curr Sports Med Rep 2010; 9(5): 299-302. [http://dx.doi.org/10.1249/JSR.0b013e3181f32056] [PMID: 20827 097]

[6] Weber CD, Nguyen AR, Lefering R, Hofman M, Hildebrand F, Pape HC. Blunt injuries related to equestrian sports: Results from an international prospective trauma database analysis. Int Orthop 2017; 41(10): 2105-12.

[http://dx.doi.org/10.1007/s00264-017-3592-1] [PMID: 28801837]

[7] Majeedkutty NA, Khairulanuar NA. Prevalence, patterns, and correlates of equestrian injuries in Malaysia: A cross-sectional study. J Family Community Med 2017; 24(1): 18-22.

[http://dx.doi.org/10.4103/2230-8229.197177] [PMID: 28163571]

[8] Von Hippel PT, Rutherford CG, Keyes KM. Gender and weight among thoroughbred jockeys: Underrepresented women and underweight men. Socius 2017; p. 3. 
[9] Wolyncewicz GEL, Palmer CS, Jowett HE, Hutson JM, King SK, Teague WJ. Horse-related injuries in children - unmounted injuries are more severe: A retrospective review. Injury 2018; 49(5): 933-8. [http://dx.doi.org/10.1016/j.injury.2017.12.003] [PMID: 29224906]

[10] Theodore JE, Theodore SG, Stockton KA, Kimble RM. Paediatric horse-related trauma. J Paediatr Child Health 2017; 53(6): 543-50. [http://dx.doi.org/10.1111/jpc.13471] [PMID: 28268253]

[11] Schröter C, Schulte-Sutum A, Zeckey C, Winkelmann M, Krettek C, Mommsen P. Accidents in equestrian sports : Analysis of injury mechanisms and patterns. Unfallchirurg 2017; 120(2): 129-38. [PMID: 26449915]

[12] Hamilton MG, Tranmer BI. Nervous system injuries in horsebackriding accidents. J Trauma 1993; 34(2): 227-32. [http://dx.doi.org/10.1097/00005373-199302000-00008] [PMID: 8459 460]

[13] Hasler RM, Gyssler L, Benneker L, et al. Protective and risk factors in amateur equestrians and description of injury patterns: A retrospective data analysis and a case - control survey. J Trauma Manag Outcomes 2011; $5: 4$.

[http://dx.doi.org/10.1186/1752-2897-5-4] [PMID: 21294862]

[14] UK Department for Transport. The Highway Code https://www.gov.uk/guidance/the-highway-code/rules-about-animals-4 7-to-58. Accessed 18 July 2018.

[15] Silver JR. Spinal injuries resulting from horse riding accidents. Spinal Cord 2002; 40(6): 264-71

[http://dx.doi.org/10.1038/sj.sc.3101280] [PMID: 12037707]

[16] British Equestrian Trade Association. Body Protection Made Easy. http://www.beta-uk.org/pages/industry-information/market-informatio n.php. Accessed 20 July 2018.

[17] Bixby-Hammett D, Brooks WH. Common injuries in horseback riding.
A review. Sports Med 1990; 9(1): 36-47.

[http://dx.doi.org/10.2165/00007256-199009010-00004] [PMID: 2408 117]

[18] ten Kate CA, de Kooter TA, Kramer W. Prevention of injuries associated with horseback riding. Ned Tijdschr Geneeskd 2015; 159: A8624.

[PMID: 25923496]

[19] Hessler C, Eckert V, Meiners J, et al. Causes, injuries, therapy and possibilities of prevention of equine-related accidents. Results of a 2center-study. Unfallchirurg 2014; 117(2): 123-7.

[http://dx.doi.org/10.1007/s00113-012-2275-z] [PMID: 23307431]

[20] O'Brien D. Look before you leap: What are the obstacles to risk calculation in the equestrian sport of eventing? Animals (Basel) 2016; 6(2): 13 .

[http://dx.doi.org/10.3390/ani6020013] [PMID: 26891334]

[21] Barone GW, Rodgers BM. Pediatric equestrian injuries: A 14-year review. J Trauma 1989; 29(2): 245-7.

[http://dx.doi.org/10.1097/00005373-198902000-00019] [PMID: 2918 566]

[22] Ingemarson H, Grevsten S, Thorén L. Lethal horse-riding injuries. J Trauma 1989; 29(1): 25-30.

[http://dx.doi.org/10.1097/00005373-198901000-00005] [PMID: 2911 099]

[23] Van Balen PJ, Barten DG, Janssen L, Fiddelers AAA, Brink PR, Janzing HMJ. Beware of the force of the horse: Mechanisms and severity of equestrian-related injuries Eur J Emerg Med 2017; 26(2): 133-8.

[24] Ki HC, Shin EK, Woo EJ, Lee E, Hong JH, Shin DH. Horse-riding accidents and injuries in historical records of Joseon Dynasty, Korea. Int J Paleopathol 2018; 20: 20-5.

[http://dx.doi.org/10.1016/j.ijpp.2017.12.001] [PMID: 29496212]

(C) 2019 Liaw et al.

This is an open access article distributed under the terms of the Creative Commons Attribution 4.0 International Public License (CC-BY 4.0), a copy of which is available at: https://creativecommons.org/licenses/by/4.0/legalcode. This license permits unrestricted use, distribution, and reproduction in any medium, provided the original author and source are credited. 